\title{
WikiFavelas: Uma Ferramenta Colaborativa para organizações sociais
}

\author{
Leonardo Gargano ${ }^{1}$, Marcelo Fornazin ${ }^{2}$ \\ ${ }^{1}$ Programa de Pós-Graduação em Informática da Universidade Federal do Rio de Janeiro \\ (PPGI/UFRJ) - RJ - Brasil \\ ${ }^{2}$ Instituto de Computação - Universidade Federal Fluminense - Niterói - Brasil \\ leoagargano@gmail.com, fornazin@ic.uff.br
}

Resumo. Observa-se que há pouco debate sobre as características de organizações sociais na área de Tecnologia da Informação (TI) e, em geral, o desenvolvimento de sistemas de software para o terceiro setor ainda assume valores e práticas da gestão empresarial, em detrimento de valores e práticas inerentes à gestão social em organizações sem fins lucrativos. Neste artigo, apresentamos uma pesquisa em andamento de uma ferramenta colaborativa para movimentos sociais. As lições, aqui compartilhadas, podem ser úteis para desenvolvedores e pesquisadores interessados em compreender e refletir sobre os desafios de desenvolver software para as organizações sociais.

\section{Introdução}

As iniciativas sociais, também chamadas terceiro setor, se apresentam como alternativas ao estado e ao mercado. Isto, pois buscam resolver problemas públicos que não são resolvidos pelo estado e nem despertam interesse nos agentes do mercado. As iniciativas sociais, embora não almejem o lucro, buscam diversas formas de parcerias para realizarem seus objetivos. Desse modo, a colaboração é um elemento fundamental para a concretização de iniciativas sociais. Neste trabalho, portanto, busca-se compreender como Sistemas de Informação (SI) podem estar associados à colaboração em iniciativas sociais. Para tanto, este artigo apresenta e discute o caso do Wikifavelas, que vem sendo usado na criação colaborativa do conhecimento para o terceiro setor.

O referencial teórico, que embasa o trabalho, articula conhecimentos de Gestão Social e colaboração em plataformas Wiki. A Gestão Social surge nos anos 1990 como alternativa ao modelo empresarial de gestão. Embora as práticas de gestão empresarial sejam amplamente empregadas em diversos setores da sociedade, autores defendem que a gestão empresarial não é universal e revela limites quando aplicada aos setores público e social (Tenório 1998; Ciborra 2005), como por exemplo, entidades filantrópicas, organizações não governamentais e movimentos sociais. Na área de SI, entretanto, ainda há pouco debate sobre as características das inciativas sociais $^{1} \mathrm{e}$, na maioria das vezes, busca-se construir sistemas e tecnologias para o terceiro setor inspirados nas práticas da gestão empresarial desconsiderando-se os valores inerentes às iniciativas sociais.

\footnotetext{
${ }^{1}$ Neste trabalho usamos o termo iniciativas sociais para nos diferenciarmos nas organizações sociais. As iniciativas sociais compreendem diversas formas organizacionais, por exemplo, ações sociais, movimentos sociais, associações e organizações sociais.
} 
Segundo Pinto (2005), as tecnologias são influenciadas e influenciam as condições culturais e sociais para quais são desenvolvidas. Portanto, é necessário desenvolver SI específicos para as organizações sociais. Desta forma, o envolvimento dos atores sociais no desenvolvimento de tecnologias é fundamental (Thiollent 2005), ou seja, a construção do software deve considerar os valores inerentes às organizações sociais e os sistemas devem ser concebidos a partir de demandas dos usuários e junto deles (Alvear 2014). Em linha com os aspectos citados e objetivando-se a fomentação do debate foi construído um software baseado na plataforma Wiki, o qual pressupõe grande participação dos usuários e sucessivas adaptações no SI à medida em que são adicionadas funcionalidades.

Assim, buscou-se compreender como sistemas colaborativos poderiam ser adaptadas ao contexto das organizações sociais de modo que o SI desenvolvido pudesse refletir as práticas dessas organizações.

\section{Referencial Teórico}

\subsection{Gestão Social}

O desenvolvimento e uso de SI majoritariamente se baseia em uma visão empresarial, a qual evidencia a importância dos sistemas na competição com concorrentes na estratégia e na geração de valor para empresas que atuam no mercado. Isso pode ser observado na definição de Turban et al. (2013): "as empresas precisam atualizar-se, desenvolver-se, e/ou implantar novos SI para se manterem na competição". A perspectiva empresarial é relevante para uma boa parte dos ambientes em que os SI são desenvolvidos e utilizados.

No entanto, um considerável número de organizações não compartilha dos valores e do modo de trabalho empresarial, como por exemplo as organizações não governamentais e movimentos sociais. Estas organizações muitas vezes operam em um ambiente não competitivo e lidam com cidadãos e/ou grupos sociais. Assim, as teorias de SI originalmente desenvolvidas nos ambientes empresariais, embora possam ser replicadas para os cenários sociais, possuem limitações, bem como efetividade questionável. Conforme Ciborra (2005) explica: “empresas segmentam mercado, e implementam várias formas de discriminação de preços, táticas que podem aumentar a desigualdade entre consumidores. Contudo, equidade de um serviço é, em princípio, o objetivo de uma administração provedora de um serviço universal".

Na gestão social "[...] a hegemonia das ações possui caráter intersubjetivo. Isto é, onde os interessados na decisão, na ação de interesse público, são participantes do processo decisório" (Tenório e Saraiva 2006), ou seja, "o foco não está nas partes, mas na interação entre as partes, não na finalidade, sim na interação entre finalidades" (Boullos e Schommer 2009). Em resumo, uma das práticas da gestão social é a tomada de decisão coletiva.

Neste trabalho busca-se, portanto, identificar como o SI é concebido coletivamente e como suas características são alteradas ao longo do tempo por meio de negociações entre os atores sociais envolvidos na construção do sistema. Além disso, acredita-se que essa negociação coletiva é fundamental para produzir motivação e engajamento nos atores e promover a colaboração. 


\subsection{Plataforma Wiki}

Ward Cunningham utilizou o termo Wiki para referenciar um novo conceito de páginas com conteúdo elaborado pelos próprios usuários. No livro The Wiki Way, o Wiki é definido como uma coleção livremente expansível de páginas Web interligadas num sistema de hipertexto para armazenar e modificar informações, onde cada página pode ser facilmente editada por qualquer usuário por meio de um navegador de internet.

O termo Wiki (Wiki é um termo havaiano que significa rápido), é utilizado para referenciar um conjunto de páginas interligadas desenvolvidas de maneira incremental. O termo também representa a expressão software social, do qual também fazem parte os blogs, listas de discussão dentre outros. Segundo Ramalho e Tsunoda (2007), wikis possuem várias finalidades: podem ser utilizados como web sites dinâmicos, ferramentas para gestão de projetos e documentos e principalmente como bases de conhecimento dinâmicas sendo adaptáveis a diversos ambientes como empresas, escolas, universidades, organizações da sociedade civil.

Ramalho e Tsunoda (2007) dizem que o espaço colaborativo criado pelo ambiente wiki, além da própria característica de sistema aberto, também deve considerar na interação dos indivíduos, o peso e importância da cooperação. $\mathrm{O}$ software wiki por ser uma ferramenta de colaboração, acaba proporcionando um ambiente de compartilhamento e produção de novos conhecimentos, estimulando a interatividade, criatividade e contribuindo para o processo de aprendizagem cooperada (Ramalho e Tsunoda 2007).

\section{Procedimentos Metodológicos}

Este trabalho foi realizado com o foco em desenvolver atividades relacionadas ao desenvolvimento e uso de SI em organizações e movimentos sociais. Assim, busca compreender os valores que guiam as ações dessas organizações. A área de SI busca compreender, de forma interdisciplinar, como indivíduos e organizações interagem com a tecnologia na busca de soluções a problemas de negócios, governos e da sociedade em geral.

Para avaliar a construção de um SI para colaboração na Gestão Social, a pesquisa foi desenhada na forma de um estudo de caso único. De acordo com Yin (2001), o estudo de caso compreende a investigação empírica de um fenômeno contemporâneo dentro de seu contexto real, especialmente quando os limites entre o fenômeno e o contexto não estão claramente definidos. $\mathrm{O}$ estudo de caso é apropriado para questões de pesquisa do tipo "como" e "por que". Assim, justifica-se a metodologia qualitativa para este trabalho. Portanto, o uso de SI na gestão social, tema desta pesquisa, encaixa-se nas características previamente citadas, uma vez que são iniciativas atualmente em curso, sobre as quais não é possível ter qualquer controle.

Baseado em Walsham (2006) foi realizado um estudo aprofundado em que os autores se envolveram com o objeto de estudo por um intervalo de tempo. A pesquisa que gerou este trabalho acompanhou o desenvolvimento do Dicionário de Favelas "Marielle Franco" no período do seu desenvolvimento entre setembro de 2017 e junho 2019. Nesse período levantou-se documentos relacionados ao caso, foram realizadas entrevistas com os atores envolvidos na construção desse SI e os autores deste artigo participaram nas atividades de planejamento e desenvolvimento do projeto. 
O material levantado foi analisado a partir de sucessivas reflexões que buscaram identificar como o SI, suas características e seu significado foram negociados ao longo tempo. Neste caso, o objetivo não foi provar uma verdade, mas compreender um cenário social de uso da tecnologia (Walsham 2006). Assim, neste trabalho não são empregadas as tradicionais técnicas de formulação de hipóteses e medição de variáveis por meio de modelos e experimentos. Por outro lado, busca-se compreender significados compartilhados emergem das relações sociais e como o SI é interpretado pelos atores sociais que interagem como ele. As reflexões formuladas a partir da análise do caso serão apresentadas na próxima seção.

\section{Estudo de Caso}

O WikiFavelas é uma plataforma virtual para produção coletiva e busca suprir uma lacuna do conhecimento transdisciplinar que é o estudo de favelas, reunindo o conhecimento produzido em vários eixos temáticos (condições socioeconômicas, políticas públicas, cultura, sociabilidade entre outros).

Inicialmente, a ideia era escrever um dicionário com verbetes sobre favelas e, além da versão impressa, publicar os verbetes na internet. Contudo, nas conversas iniciais, a equipe técnica sugeriu que o Dicionário fosse desvinculado do suporte físico do papel e explorasse todo o potencial das redes digitais para a construção colaborativa desse corpo de conhecimento. A ideia de um dicionário virtual colaborativa foi apresentada a um grupo de pessoas que se motivaram com o projeto e, posteriormente, integraram o conselho editorial do Dicionário.

Uma vez definida a ideia geral do Dicionário, os integrantes passaram e discutir formas de financiamento do projeto para construção do Dicionário. O trabalho de busca por recursos durou praticamente o ano de 2017 e 2018. Por se tratar de uma iniciativa social a qual não possui geração de receita própria, foi necessário buscar fomento em diversas agências. Com o fomento ao projeto viabilizado durante o ano de 2018 foram realizadas diversas reuniões para conceituação do Dicionário e mobilização dos colaboradores. Em março de 2019, o Dicionário foi lançado com 140 verbetes, uma centena de colaboradores cadastrado e desde então têm sido feitas novas colaborações ao Dicionário. A Figura 1 ilustra a página principal do Dicionário.

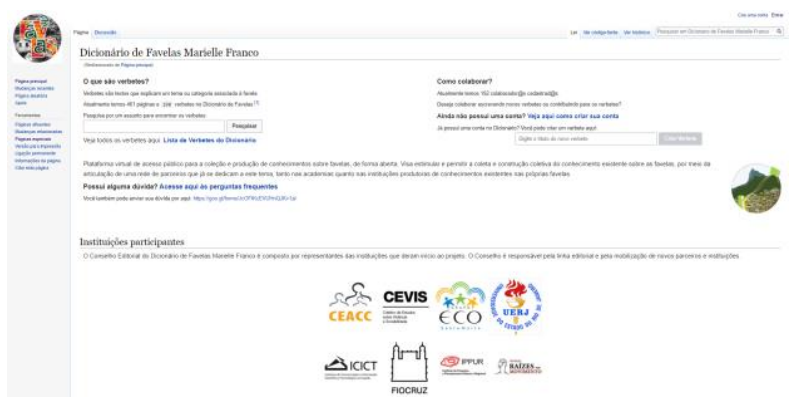

Figura 1. Página Principal do Wikifavelas.

A partir das interações com os colaboradores do Wikifavelas foi possível identificar dois grupos principais: os acadêmicos e as lideranças sociais. Os acadêmicos geralmente são professores, pesquisadores e estudantes de instituições de ensino superior, os quais realizam pesquisas sobre as favelas. As lideranças sociais são representantes de organizações sociais e projetos que trabalham com questões das 
favelas. Ainda que alguns colaboradores sejam tanto acadêmicos quanto lideranças sociais, foi possível também identificar similaridades e diferenças em seus interesses e comportamentos.

O principal elemento de ligação entre os diversos colaboradores é o interesse pelo tema favela, que alia à vontade por dar visibilidade a riqueza histórica, cultural e social das favelas à preocupação e evidenciar as dificuldades que os moradores de favelas enfrentam em seu cotidiano. Também foram observadas diferenças, por exemplo, na questão da autoria e da preservação do conteúdo. Os acadêmicos estão acostumados a ter o reconhecimento da autoria e valorizam esse registro. As lideranças sociais manifestaram preocupação com a preservação e a proteção dos acervos e da memória das favelas.

Assim, foi necessário ouvir, analisar as considerações e ajustar o SI para atender as demandas dos colaboradores e produzir engajamento para a colaboração. A partir dessa escuta foram propostos arranjos técnicos e organizacionais que contemplassem os diferentes interesses e fomentassem o trabalho coletivo. Exemplos de arranjos organizacionais são o Conselho Editorial e os Grupos de Trabalho do Dicionário. O Conselho Editorial possui representantes da acadêmica e dos movimentos sociais e se reúne bimestralmente para discutir as atividades do Dicionário e elaborar orientações para futuro do Dicionário. Os Grupos de Trabalho, por sua vez, realizam um acompanhamento da produção de verbetes e motivam os colaboradores a aprimorarem e produzirem novos conteúdos. Em relação à tecnologia, foram realizadas diversas adaptações na plataforma Wiki, as quais passam por alterações de layout, instalação de plug-ins para conteúdos multimídia e produção das guias e manuais para edição do conteúdo na Wikifavelas.

\section{Conclusões e Trabalhos Futuros}

O desenvolvimento de SI para gestão social ainda é pouco explorado na área de TI. O objetivo desta pesquisa foi iniciar por meio de um estudo de caso discussões futuras acerca do tema TI e gestão social.

Como resultados, apresentamos as reflexões sobre o processo de construção de um software na área social o "Dicionário Favelas Marielle Franco". A partir dessa experiência foi possível observar que a construção do SI na área social não seguiu os objetivos empresariais, tais como retorno financeiro ou vantagem competitiva, mas buscou promover a colaboração e o valor público compartilhado do conhecimento produzido por diversos sujeitos sociais.

Ao construir um SI para um projeto de cunho social, não se buscou atingir metas pré-estabelecidas, mas construir coletivamente os objetivos do projeto, bem como conhecimentos, à medida que o projeto se desenrolava. Ou seja, neste projeto mais importante do que seus objetivos iniciais, foi o caminho trilhado para a construção do SI.

Algumas limitações podem ser destacadas, como o uso de apenas um estudo de caso, mas as conclusões tiradas desse estudo podem ser aplicadas a outros estudos do mesmo cunho social. Durante a escrita deste artigo, o software estava liberado oficialmente há pouco tempo, assim não tivemos as estatísticas do uso público do software (apenas das instituições participantes) e ainda há poucos exemplos de softwares específicos para esse segmento. 
Existem diversas dificuldades no desenvolvimento de software das quais se destacam: fatores culturais organizacionais e regionais, conflitos de comunicação e comportamentais entre os stakeholders, entre outros (Prikladnicki e Audy 2006). Herbsleb (2005) corrobora com este entendimento, afirmando que é necessário compreender o comportamento dos engenheiros de software, das equipes de desenvolvimento, e da organização como um todo, bem como, suas práticas sociais e culturais. Portanto, para atingir qualidade e eficácia nas atividades cotidianas, além de fatores técnicos, os fatores humanos também devem receber especial atenção.

Ainda assim, há muito a ser feito e trabalhos futuros podem investigar processos de comunicação com stakeholders, bem como compreender melhor quais motivações levam os usuários, muitos deles voluntários, a participarem na área social.

\section{Referências}

Ciborra, C. (2005). Interpreting e-government and development: Efficiency, transparency or governance at a distance? Information Technology \& People. 260279.

Tenório, F. (1998). Gestão Social: uma perspectiva conceitual. Revista de Administração Pública, 32, 5, 7-32.

Alvear, C. A. S. (2014). Tecnologia e Participação: Sistemas de Informação e a construção de propostas coletivas para movimentos sociais e processos de desenvolvimento local (Tese). http://www.producao.ufrj.br/index.php/br/teses-edissertacoes/teses-e-dissertacoes/doutorado/2014-1/50--43

Pinto, A. V. (2005). O conceito de tecnologia. Contraponto, Rio de Janeiro

Turban, E. e Volonino, L. (2013). Tecnologia da Informação para Gestão: em busca do melhor desempenho estratégico e operacional. Bookman, Porto Alegre.

Tenório, T.G e Saraiva, H. J. Escorços sobre gestão pública e gestão social. In Martins, P. E. M.; Pieranti, O. P. Estado e gestão pública: visões do Brasil contemporâneo. 2 Ed. Rio de Janeiro: FGV, 2006, 340p

Boullos A, R. de F.; Schommer, P. C. (2009). Gestão social: caso de inovação em políticas públicas ou mais um enigma de lampedusa? In Encontro Nacional de Pesquisadores em Gestão Social, 3, Juazeiro/Petrolina.NIGS/UNIVASF, 2009. 1 CD ROM

Ramalho, L. e Tsunoda, D. F. (2007). Collaborative Building of Knowledge from USE of Wiki Tools. VIII ENANCIB - Encontro Nacional de Pesquisa em Ciência da Informação, Salvador, Brasil

Prikladnicki, R. e Audy, J. L. N. (2006). Construção do Conhecimento e Complexidade na Área de Engenharia de Software II WORKSHOP Um olhar sociotécnico sobre a engenharia de software

Herbsleb. J. D. (2005). Beyond Computer Science. Proceedings of the 27 International Conference on Software Engineering (ICSE). St. Louis, Missouri, EUA, 23-27

Yin, R. (2001). Estudo de caso: planejamento e métodos. Bookman, Porto Alegre.

Walsham, G. (2006). Doing interpretive research. European Journal of Information Systems, 320-330 